\title{
Consumer Fraud in America: The Latino Experience
}

2 in 5 (39\%) Latino adults have been the target of a scam
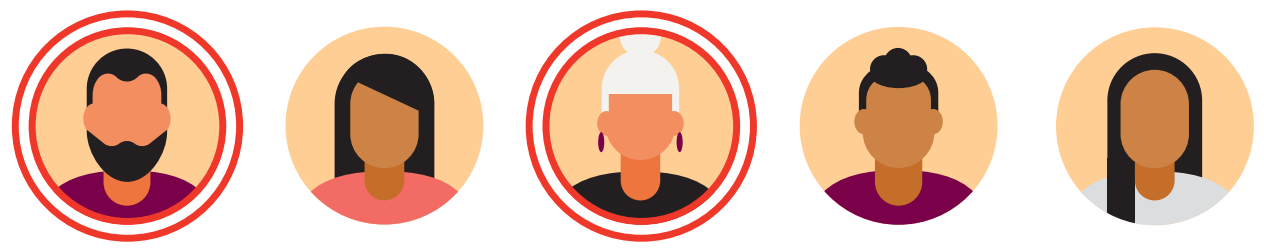

1 in 5 (21\%) lost money to a scam
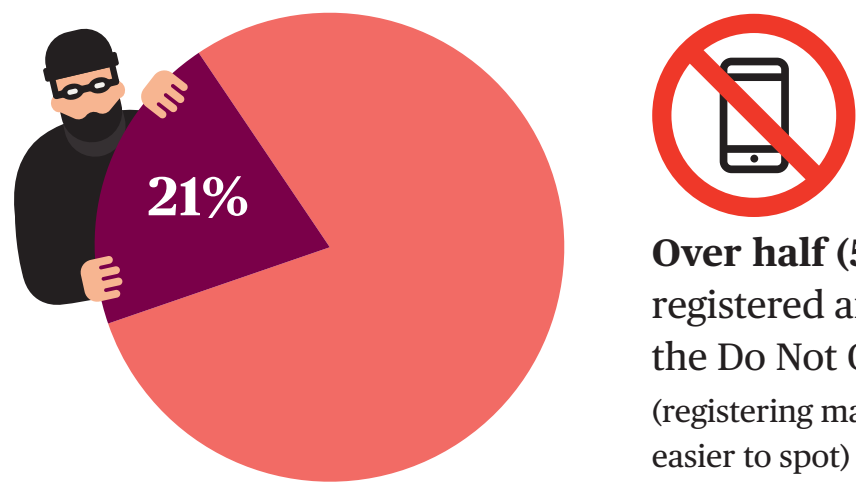

Over half (58\%) have not registered any phone on the Do Not Call Registry (registering makes scam calls easier to spot)

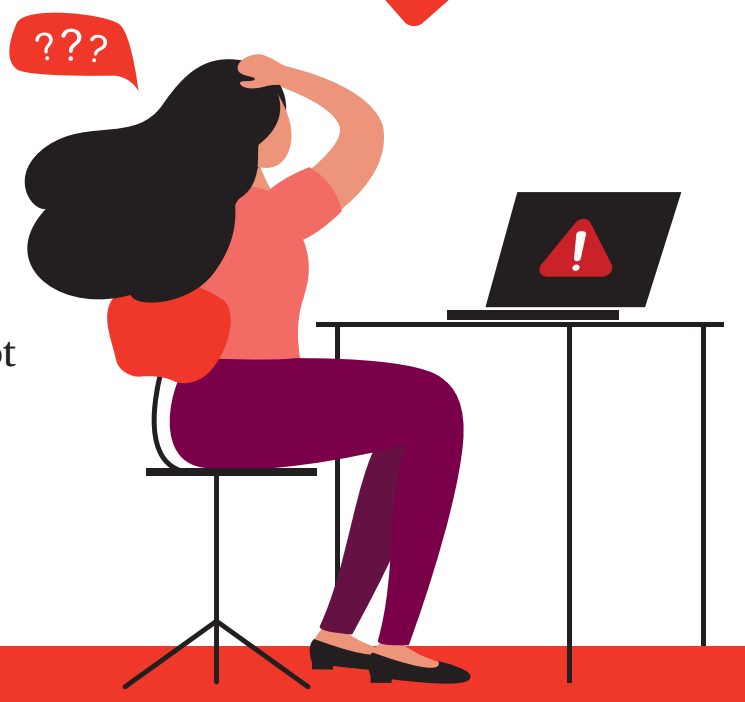

\section{PASSWORD}

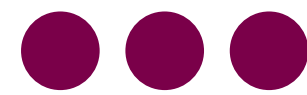

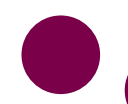

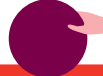

For questions on this issue,

please contact Kathy Stokes, Director of AARP Fraud Prevention Programs, at kstokes@aarp.org.

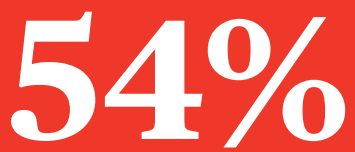

of Latino adults report using the same password on a few or all accounts or a variation of the same password for all accounts (which increases the risk of fraud loss across accounts)

For media inquiries, please contact Emily James, AARP External Relations, at ejames@aarp.org.

For questions regarding the survey and methodology, please contact Jennifer Sauer at jsauer@aarp.org. 